\title{
Análise do conhecimento de professores de Educação Infantil sobre saúde bucal
}

\section{Analysis of teacher knowledge of early Childhood Education on oral health}

\author{
Renato Moreira Arcieri ${ }^{1}$ \\ Tânia Adas Saliba Rovida ${ }^{2}$ \\ Daniela Pereira Lima ${ }^{3}$ \\ Artênio José Isper Garbin ${ }^{4}$ \\ Cléa Adas Saliba Garbin ${ }^{5}$
}

\begin{abstract}
RESUMO
A figura do professor exerce grande influência sobre o comportamento dos alunos, pelo contato diário durante longo tempo. O objetivo do presente trabalho foi analisar o conhecimento dos professores de escolas estaduais e municipais de educação infantil no que diz respeito à saúde bucal. Foi realizado um estudo exploratório descritivo, com abordagem quanti-qualitativa com 164 professores, utilizando-se um questionário, autoaplicável, com perguntas sobre o tema. Os mesmos foram digitados e analisados pelo programa Epi Info, 3.5.1. Entre os resultados obtidos, pode-se observar que $94,5 \%$ relataram atuar em escolas que possuem atividades de educação em saúde bucal. Sobre as informações a respeito dos cuidados necessários
\end{abstract}

${ }^{1}$ Doutor em Odontologia pela Universidade Estadual Paulista Júlio de Mesquita Filho da Faculdade de Odontologia de Araçatuba (UNESP/FOA). Professor Assistente do Departamento de Odontologia Infantil e Social da (FOA/UNESP); Brasil. E-mail: rarcieri@foa.unesp.br

${ }^{2}$ Doutora em Odontologia Legal e Deontologia pela Universidade Estadual de Campinas (UNICAMP). Professora Assistente do Departamento de Odontologia Infantil e Social da FOA da UNESP/Araçatuba; Brasil. E-mail: tasalibarovida@foa.unesp.br

${ }^{3}$ Doutoranda do programa de Pós-graduação em Odontologia Preventiva e Social da FOA/ UNESP; Brasil. E-mail: dani.pl@hotmail.com

${ }^{4}$ Doutor em Ortodontia pela UNICAMP. Professor Adjunto do Departamento de Odontologia Infantil e Social da FOA/UNESP; Brasil. E-mail: agarbin@foa.unesp.br

${ }^{5}$ Doutora em Odontologia Legal e Deontologia pela UNICAMP. Professora Adjunta do Departamento de Odontologia Infantil e Social da FAO/UNESP/Araçatuba; Brasil. E-mail: cgarbin@foa.unesp.br 
para a manutenção da saúde bucal, 85,4\% relataram ter recebido em algum momento. Segundo eles, a informação foi fornecida principalmente pelo cirurgião dentista (64,3\%), alunos FOA-UNESP (16,4\%), família (5,7\%). $95,7 \%$ responderam saber o que é cárie dentária. Dentre esses indivíduos, $12,2 \%$ relacionaram-na a resíduos acumulados no dente. No que se refere à função do flúor em relação à cárie dentária, 88,4\% indicaram conhecê-la. Destes, 50,3\% atribuíram ao mesmo a função de proteção da estrutura dental. Pode-se concluir que embora a escola seja um espaço importante de informação, esta é ainda muito pouco aproveitada, os professores possuem pouco conhecimento a respeito dos cuidados necessários para a manutenção da saúde bucal e necessitam de maiores informações para abordarem com segurança estes temas em sala de aula.

Palavras-chave: Educação Infantil; educação em saúde; saúde bucal.

\begin{abstract}
The teacher's image causes high influence on students' behavior, through daily contact during long time. The objective of this study was to examine the knowledge of teachers from state and municipal primary schools, about oral health. It was performed a descriptive and exploratory study with an quantitative and qualitative approach including 164 teachers, using as instrument, self-applied questions about the theme. The data was stored and analyzed by Epi Info Program version 3.5.1. Among the results, it was possible to observe that $94,5 \%$ related to work in primary schools that have activities about oral health education. In relation to information about necessary cares, $85,4 \%$ related to have received it during some moment. According to them, the information was given mainly by dentist $(64,3 \%)$, students of Araçatuba Dental School (16,4\%) and family (5,7\%). 95,7\% answered they know the meaning of dental caries and among them, 12,2\% related it to food remaining on teeth, $88,4 \%$ said to know it. Among these perceptual, $50,3 \%$ attributed to the same role to protection of dental structure. It is possible to conclude that although the school is an important place for information, but it is not fully used; the teachers have little knowledge about the necessary care for maintenance of oral health, and need more information for approaching with security these themes during classes.
\end{abstract}

Keywords: Child Day Care Centers; health education; oral health. 


\section{Introdução}

A prevalência de cárie dentária no Brasil ainda é bastante alta e o ciclo restaurador repetitivo é uma realidade, acarretando em ônus para o sistema de saúde e comprometimento da capacidade funcional do cidadão. Na mesma situação encontra-se a doença periodontal, com elevado índice na população adulta e segunda causa de perda dental nesta faixa etária. Sabe-se que a eficácia da terapêutica instituída no combate a estas patologias não depende somente do conhecimento científico e da habilidade técnica do profissional, mas também do apoio do paciente na busca de um efetivo controle da placa bacteriana, principal fator etiológico de ambas as enfermidades (CAMPOS et al., 2008).

Segundo dados do último levantamento nacional para a cárie dentária, realizado em 2003, o Brasil atingiu as metas propostas pela OMS para o ano 2000 somente no grupo etário de 12 anos nas regiões Sul e Sudeste (BRASIL, 2004).

Unfer e Saliba (2000) salientam a importância do esclarecimento da população, enfatizando a possibilidade de intervenção precoce no controle dos problemas de saúde, podendo a partir daí evitar tratamentos restauradores e reabilitadores, visto que estes não restituem plenamente a saúde bucal.

De acordo com Garcia et al. (2000), a prevenção é a maneira mais econômica e eficaz de se evitar o aparecimento e desenvolvimento das principais doenças bucais. Dentro das várias atividades preventivas, a educação e a motivação do indivíduo ocupam lugar de destaque e devem ser aplicadas com o objetivo de mudar hábitos e comportamentos, no sentido de promover a saúde e melhorar a higiene bucal do paciente (BRANDÃO, 1998; BROOK et al., 1996; D'ALMEIDA et al., 1997). Contudo, segundo Blinkhorn (1993), na maioria das vezes, a mudança de hábito é muito difícil de ser atingida em virtude de influências sociais, culturais e governamentais que ocasionam uma verdadeira inversão de valores.

Neste sentido, para que o cirurgião-dentista consiga promover a educação, faz-se necessária a utilização de estratégias e métodos adequados de motivação e, principalmente, reforço das informações (SANTOS et al., 2003). A continuidade da motivação é a responsável pela sedimentação dos conhecimentos, caso contrário de nada adiantarão os esforços iniciais, que provavelmente se perderão com o tempo (SANTOS et al., 2002).

De acordo com Garbin et al. (2009), a educação em saúde bucal para crianças é fundamental para a diminuição do risco à cárie dentária desta população, pois esta pode evoluir rapidamente, afetando de forma imediata a qualidade de vida da criança e de seus familiares (ROZIER et al., 2003). Nesta fase da 
vida, as constantes mudanças no ambiente bucal e a facilidade de aprendizagem acarretam a modificação de hábitos errôneos (GARBIN et al., 2009).

Desta forma, a escola é o local ideal para o desenvolvimento de programas educativo-preventivos, pois agrega todas as crianças, incluindo até aquelas que por algum motivo não têm acesso aos cuidados profissionais particulares (LOUPE et al., 1983).

Sendo assim, a coparticipação entre dentistas e professores na veiculação de informações sobre saúde e higiene bucal para as crianças torna-se de grande valia (PAIVA et al., 1992), uma vez que a figura do professor exerce grande influência sobre o comportamento dos alunos, pelo contato diário durante longo tempo (SANTOS et al., 2003).

O conhecimento e as atitudes dos professores de educação infantil, no que diz respeito à etiologia, prevenção e evolução da cárie dentária e da doença periodontal, devem ser cuidadosamente avaliados e, se necessário, revistos, para que esses educadores possam trabalhar em conjunto com o cirurgião-dentista, contribuindo para o sucesso de programas educativos (WYNE et al., 2002).

Deste modo, diversos autores (SGAN-COEN et al.; 1999; ALMAS et al.; 2003) têm realizado estudos com o objetivo de entender as diversas realidades e o conhecimento sobre saúde bucal de professores de ensino infantil, para elaboração de propostas que incluam este grupo nas ações de prevenção voltadas às crianças.

Diante do exposto, o objetivo desse estudo foi avaliar o conhecimento dos professores de escolas estaduais e municipais de educação infantil do município de Araçatuba-SP, no que diz respeito à saúde bucal.

\section{Metodologia}

A pesquisa, caracterizada como um estudo exploratório descritivo, com abordagem quanti-qualitativa, foi aprovada pelo Comitê de Ética em Pesquisa da Faculdade de Odontologia de Araçatuba, Universidade Estadual Paulista, Brasil, processo 2006-01202.

O universo amostral foi obtido a partir de todos os professores de escolas estaduais e municipais de educação infantil $(n=232)$ que lecionavam no ano letivo de 2010 no município de Araçatuba-SP. O grupo de professores que integraram a pesquisa foi organizado com base em dois critérios: possuir formação em nível superior e aceitar participar da pesquisa. 
Os dados foram coletados por meio de questionário estruturado, autoaplicado, com perguntas abertas e fechadas que abordaram o conhecimento por parte dos professores sobre o tema. O mesmo foi elaborado com base no instrumento proposto por Campos e Garcia (2004), especialmente elaborado para pesquisa. Todos os professores participantes assinaram o Termo de Consentimento Livre e Esclarecido.

Para análise quantitativa dos dados foi utilizado o software Epi Info versão 3.5.1. (DEAN et al., 1990), por meio da distribuição das frequências e porcentagens. Para a análise qualitativa, utilizou-se a análise de conteúdo, por meio da técnica de análise de categorias (BARDIN, 2004). Esta técnica visa ao agrupamento de circunstâncias que dão sentido ao fato, oferecendo liberdade para resgatar o importante na novidade dos temas, mesmo se a frequência é pequena. Ou seja, categorias surgiram de acordo com as respostas dadas pelos professores e aquelas que possuíam o mesmo sentido foram agrupadas na mesma categoria, mesmo que elas fossem ditas de maneira diferente.

\section{Resultados e discussão}

Do total de 232 professores de escolas estaduais e municipais que lecionavam no ano de 2010 , em Araçatuba-SP, 70,6\% $(\mathrm{n}=164)$ possuíam nível superior e consentiram participar do estudo.

A Tabela 1 relaciona as respostas dos sujeitos da pesquisa quanto às perguntas referentes às atividades de educação em saúde realizadas nas escolas em que trabalham, sendo que $94,5 \%$ relataram atuar em escolas que possuem atividades de educação em saúde bucal. Todos os professores $(n=164)$ acreditam ser importante a realização dessas atividades e afirmaram tratar desses temas em suas salas de aulas. Martins et al. (2008) encontraram resultados semelhantes, onde a maioria dos professores $(78,4 \%)$ afirmou abordar temas referentes à saúde bucal com seus alunos. Entretanto, Vasconcelos et al. (2001), obtiveram resultados diferentes do exposto, relatando que $64 \%$ dos professores participantes de sua pesquisa nunca abordaram conteúdos referentes à saúde geral e bucal em sala de aula e, dos $36 \%$ restantes, $8 \%$ o faziam ocasionalmente. 
Tabela 1 - Distribuição de frequência e percentual das respostas, referentes às questões sobre as atividades de educação em saúde realizadas nas escolas municipais e estaduais de educação infantil. Araçatuba-SP, Brasil, 2010

\begin{tabular}{l|c|c|c|c}
\hline \multirow{2}{*}{ Questões } & \multicolumn{3}{c}{ Respostas } \\
\cline { 2 - 5 } & \multicolumn{2}{c|}{ Sim } & \multicolumn{2}{c}{ Não } \\
\cline { 2 - 5 } & $\mathrm{n}$ & $\%$ & $\mathrm{n}$ & 5.5 \\
\hline $\begin{array}{l}\text { 1. Na escola em que você trabalha são realizadas } \\
\text { atividades de educação em saúde bucal? }\end{array}$ & 155 & 94.5 & 09 & 0 \\
\hline $\begin{array}{l}\text { 2. Você acha isso importante? } \\
\text { 3. Durante suas aulas você aborda temas referentes à } \\
\text { saúde? }\end{array}$ & 164 & 100 & 0 & 0 \\
\hline $\begin{array}{l}\text { 4. Nestes temas estão incluídos cuidados com a saúde } \\
\text { bucal? }\end{array}$ & 164 & 100 & 0 & 0 \\
\hline
\end{tabular}

A dificuldade para tratar de conteúdos sobre saúde bucal é ratificada quando se observa que apenas $15,8 \%$ dos temas citados pelos pesquisados se referem a questões sobre o assunto (Gráfico 1). Verifica-se ainda uma limitação, pois a grande parte enfoca apenas tópicos de higiene bucal, negligenciando os demais assuntos. Vasconcelos et al. (2001) explicam que o fato de a escola discutir pouco os conceitos de saúde bucal se deve à falta de conhecimento sobre o assunto e escassez de tempo disponível. Assim, a inclusão dos conteúdos relacionados à saúde bucal nos currículos das escolas de educação infantil contribuiria para que a abordagem destes temas em salas de aula fosse mais aprofundada e frequente.

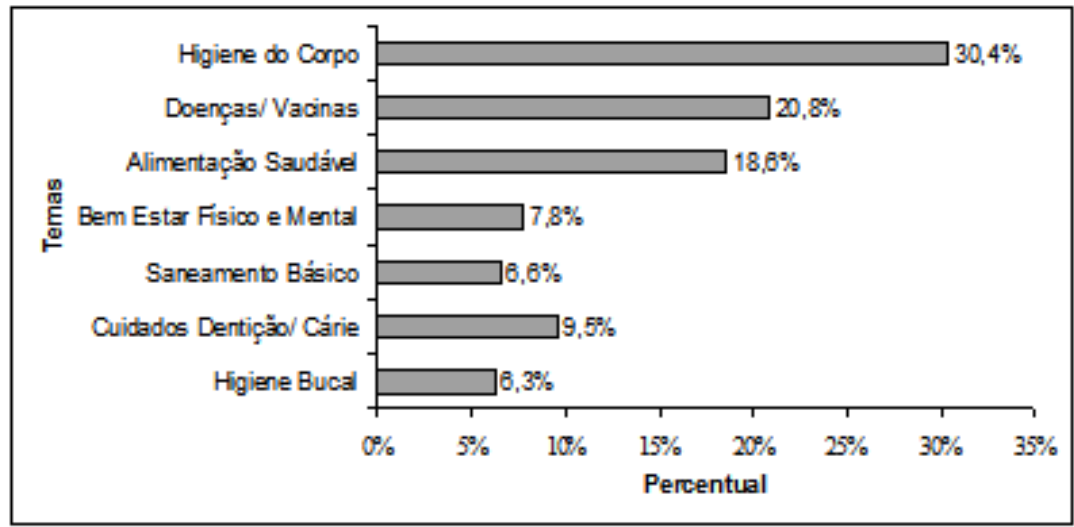

Gráfico 1 - Distribuição percentual dos temas relacionados à saúde desenvolvidos por professores de educação infantil. Araçatuba-SP, Brasil, 2010 
A maior parte dos professores, $85,4 \%(n=140)$, relatou ter recebido informações a respeito dos cuidados necessários para a manutenção da saúde bucal e os resultados indicam o acesso dos participantes do estudo à informação sobre saúde bucal (Tabela 1). Em estudos semelhantes, Santos et al. (2002) observaram valores acima do encontrado: 91,67\%. Todavia, Vasconcelos et al. (2001) verificaram que apenas $44 \%$ dos participantes afirmaram ter acesso a informações sobre saúde bucal.

Muito embora não haja uma integração formal entre professores e cirurgiões-dentistas, observou-se que os professores reconhecem nos profissionais da Odontologia uma importante fonte de informações, tendo estes papel de destaque em nossa pesquisa: 64,2\% (Tabela 2). Trabalhos realizados por Al-Tamimi e Petersen (1998), Lang e Woolfolk (1989), Oliveira (1996), em diferentes países, também destacaram o dentista como principal fonte de informações, representando $82,3 \%, 78 \%$ e $39,3 \%$ da população estudada, respectivamente. Por sua vez, Petersen e Esheng (1998) e Petersen et al. (1995) apontaram a televisão como a mais citada e o dentista surge na $6^{\mathrm{a}}$ e $5^{\mathrm{a}}$ colocações, respectivamente.

É importante ressaltar o papel da universidade como fonte de conhecimento sobre saúde bucal. No presente trabalho, apenas $1,5 \%$ citou sua graduação como fonte de informações (Tabela 2). Isso é preocupante, uma vez que os professores devem possuir conhecimento adequado sobre saúde bucal para que possam transmiti-los às crianças e o seu desconhecimento odontológico pode influenciar de forma negativa seus respectivos alunos.

Tabela 2 - Distribuição numérica e percentual, segundo o responsável pela informação sobre cuidados de saúde bucal. Araçatuba-SP, 2010

\section{Responsável pela informação}

Cirurgião dentista de consultório particular

\begin{tabular}{cc}
$\mathbf{n}$ & $\mathbf{\%}$ \\
90 & 64,3 \\
23 & 16,4 \\
8 & 5,7 \\
3 & 2,2 \\
2 & 1,5 \\
2 & 1,5 \\
2 & 1,5 \\
1 & 0,6 \\
1 & 0,6 \\
8 & 5,7 \\
$\mathbf{1 4 0}$ & $\mathbf{1 0 0}$ \\
\hline
\end{tabular}


Verificou-se que $85,4 \%(\mathrm{n}=140)$ afirmaram saber o que é placa dentária bacteriana e, quando foram solicitados a descrevê-la, encontraram-se as mais variadas respostas. A Tabela 3 apresenta as respostas categorizadas a respeito da opinião dos professores sobre o que seria a placa bacteriana dental. A associação do conceito de placa bacteriana à categoria "bactérias" foi a mais citada (26,4\%). Estudo realizado por Santos et al., em 2002, observou que, dos indivíduos que consideraram saber o que é placa bacteriana, $40 \%$ relacionaram sua presença a restos alimentares.

Nota-se que existem distorções de conceitos entre os sujeitos da pesquisa. É provável que essa confusão seja de responsabilidade dos próprios cirurgiões-dentistas que, para simplificarem a educação e a comunicação, acabam usando termos que criam conceitos inadequados entre os pacientes, como a relação "sujeira acumulada" ou "acúmulo de alimentos" à placa bacteriana. Como o próprio nome diz, a placa bacteriana é inicialmente formada por grupos de micro-organismos que se aderem à superfície dental (LINDHE, 1992).

Tabela 3 - Distribuição de frequência absoluta e percentual das categorias referentes às respostas positivas dadas pelos professores sobre o que é placa bacteriana, Araçatuba-SP, 2010

\begin{tabular}{l|c|c}
\hline \multicolumn{1}{c|}{ Categorias } & \multicolumn{2}{c}{ Frequência } \\
& $\mathbf{n}$ & $\mathbf{\%}$ \\
Bactérias - "Bactérias que permanecem nos dentes, e nas & 37 & 26.4 \\
gengivas". & & \\
Tártaro - "É uma película denominada tártaro". & 22 & 15.8 \\
Acúmulo de alimento - "Alimentos acumulados entre os dentes que & 21 & 15.0 \\
solidificam". & & \\
Sujeira acumulada - "É uma sujeira acumulada que fica no dente”. & 20 & 14.3 \\
Resíduos - "São resíduos que se formam no dente que não é & 17 & 12.2 \\
devidamente higienizado". & & \\
Mancha nos dentes - "Mancha preta no dente”. & 6 & 4.2 \\
Cárie - "É a cárie”. & 2 & 1.4 \\
Outros - "Consequência de má escovação". & 1 & 0.7 \\
Não respondeu & 14 & 10.0 \\
Total & $\mathbf{1 4 0}$ & $\mathbf{1 0 0}$ \\
\hline
\end{tabular}

Observou-se que 95,7\% $(\mathrm{n}=157)$ responderam saber o que é cárie dentária. Dentre esses indivíduos, $12,2 \%$ a relacionaram com resíduos acumulados no dente. Outros $(33,1 \%)$ ainda associaram-na a alterações físicas no dente, ou seja, os seus sinais, como buraco, perfuração e desgaste. Um grupo de professores 
$(17,8 \%)$ referiu-se à presença de bactérias, sem, contudo, explicar o papel destas no processo da doença, $24,2 \%$ relacionou-a com a descalcificação e decomposição do esmalte e dentina em virtude da ação dos ácidos das bactérias, enquanto que $12,7 \%$ associaram-na a doença nos dentes (Tabela 4 ).

Pesquisa realizada por Unfer e Saliba (2000), os quais observaram conhecimentos sobre saúde bucal de usuários de serviço público, verificaram que $27,5 \%$ da população estudada referiram-se à cárie dental como alteração física no dente, $23,1 \%$ à bactéria e $22,6 \%$ à falta de higiene. Tal fato mostra que, embora existam algumas deficiências, os indivíduos da presente pesquisa tinham maiores conhecimentos sobre a cárie dental.

Tabela 4 - Distribuição de frequência absoluta e percentual das categorias referentes às respostas positivas dadas pelos professores sobre o que é cárie dental, Araçatuba-SP, 2010

\section{Categorias}

\section{Frequência \\ n $\%$}

Resíduos acumulados - "São resíduos acumulados". $19 \quad 12,2$

Alterações físicas nos dentes - "São furinhos nos dentes". $52 \quad 33,1$

Presença de bactérias - "São bactérias que se alojam nos dentes, prejudicando".

Descalcificação do esmalte - "Ocorre quando ácidos descalcificam os dentes".

Doença nos dentes - "Uma doença que destrói os dentes".

$20 \quad 12,7$

Total

157

Sobre a etiologia da cárie, $81,4 \%(\mathrm{n}=101)$ dos professores que responderam saber o porquê de sua ocorrência condicionaram seu aparecimento com a má higiene bucal. Resultados semelhantes foram encontrados no estudo de Almas et al. (2003), em que $88 \%$ de seus entrevistados acreditam que a cárie dentária é resultante da má escovação. Quanto à multifatoriedade que leva ao surgimento da cárie dental, nosso estudo reflete baixo nível de conhecimento dos participantes, uma vez que nenhum dos professores citou essa característica da doença. Em pesquisa realizada por Ferreira et al. (2005), a multifatoriedade foi citada por $55 \%$ dos entrevistados. Resultados diferentes foram observados por Santos et al. (2002), onde a mesma foi citada por $20,4 \%$ dos sujeitos da pesquisa.

É preocupante verificar que o conhecimento dos professores sobre temas básicos de saúde bucal ainda é muito limitado. Estes fatos demonstram a necessidade de se trabalhar, nos cursos de formação de professores, conteúdos ligados à saúde e à higiene bucal, objetivando fornecer aos profissionais da educação habilidades básicas para o ensino destes temas (FOCESI 1990). 
Tabela 5 - Distribuição de frequência absoluta e percentual das categorias referentes às respostas positivas dadas pelos professores sobre o fator etiológico da cárie dental, Araçatuba-SP, 2010

\section{Categorias}

Frequência

Falta de higiene bucal - "Falta de higienização bucal ou não uso de fio dental."

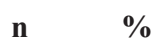

Dieta- "Consumo excessivo de açúcar."

$101 \quad 81,4$

Bactérias - "Bactérias que perfuram o dente."

Outros - "A placa bacteriana."

No que se refere à função do flúor em relação à cárie dentária, 145 professores $(88,4 \%)$ indicaram conhecê-la. Destes, $50,3 \%$ atribuem ao mesmo a função de proteção da estrutura dental, $22,0 \%$ de prevenção contra a cárie, $18,0 \%$ de fortalecimento da estrutura dental (Tabela 6). Todas as respostas estão corretas se considerarmos a função do flúor de maneira simplificada e abrangente, que é como a classe odontológica frequentemente ensina: prevenir cáries. Porém, a questão é como o flúor age para preveni-las. Essas informações devem fazer parte do cotidiano dos professores, pois são eles que trabalham durante um longo período com as crianças, podendo assim explicar aos seus alunos o que acontece com seus dentes quando eles fazem o bochecho com flúor, bem como quais os cuidados que devem ser observados após a sua aplicação.

Tabela 6 - Distribuição de frequência absoluta e percentual das categorias referentes às respostas positivas dadas pelos professores sobre a função do flúor em relação à cárie dentária, Araçatuba - SP, 2010

\section{Categorias}

Proteção - "Proteger o esmalte do dente."

Prevenção - “Ajuda na prevenção da cárie."

Fortalecimento -"Fortalece os dentes reduzindo a cárie dentária."

Outros- "Limpeza dos dentes."

Não respondeu

Total

O aumento da resistência do esmalte contra a cárie dental foi citado por $86,3 \%$ dos professores na pesquisa de Sgan-Cohen et al. (1999). Por outro lado,
Frequência

\begin{tabular}{cc}
$\mathbf{n}$ & \% \\
73 & 50,3 \\
32 & 22,0 \\
26 & 18,0 \\
8 & 5,5 \\
6 & 4,2 \\
$\mathbf{1 4 5}$ & $\mathbf{1 0 0}$ \\
\hline
\end{tabular}


Petersen et al. (1995) encontraram 72\% dos respondentes referindo-se ao flúor como meio de prevenção das cáries. Ainda, Chikte et al. (1990b) e Petersen et al. (2000) verificaram que $42 \%, 42 \%$ e $72 \%$, respectivamente, não sabiam nem o que é o flúor, quanto mais sua função.

Quando questionados sobre os lugares onde o flúor pode ser encontrado, $42,8 \%$ citaram as águas de abastecimento público, 29,8\% no creme dental, 10,6\% em farmácias, 5,6\% em consultórios odontológicos, 3,3\% em lojas especializadas, $2,1 \%$ em supermercados, 1,4\% em Unidades Básicas de Saúde, 2,1\% outros e 2,1\% não responderam. Entretanto Unfer e Saliba (2000) verificaram que o cirurgião dentista foi citado por $26,2 \%$ dos entrevistados, enquanto a água por $5,6 \%$, sugerindo a necessidade de divulgação da importância deste veículo. Já Chikte et al. (1990b) observaram que 58\% dos indivíduos avaliados referiram-se às pastas de dente como fonte de flúor.

\section{Conclusão}

Mediante a metodologia aplicada, pode-se concluir que, embora a escola seja um espaço importante de informação, esta é ainda muito pouco aproveitada, os professores possuem pouco conhecimento a respeito dos cuidados necessários para a manutenção da saúde bucal e necessitam de maiores informações para abordarem com segurança estes temas em sala de aula. A inclusão destes educadores dentro dos programas educativo-preventivos em saúde bucal é uma ferramenta indiscutível para transmissão de conhecimento e, desta forma, informações corretas e completas poderão ser assimiladas e multiplicadas dentro do processo de interação professor-aluno.

\section{REFERÊNCIAS}

ALMAS, K.; AL-MALIK, T. M.; AL-SHEHRI, M. A.; SKAUG, N. The knowledge and practices of oral hygiene methods and attendance pattern among school teachers in Riyadh, Saudi Arabia. Saudi Med. J., Saudi Arabia, v. 24, n. 10, p. 1087-1091, 2003.

AL-TAMIMI, S.; PETERSEN P. E. Oral health situation of schoolchildren, mothers and schoolteachers in Saudi Arabia. Int. Dent. J., England, v. 48, n. 3, p. 180-186, 1998. 
BARDIN, L. Análise de conteúdo. 3. ed. Lisboa: Ed. 70, 2004.

BLINKHORN, A. S. Fatores que afetam a adesão dos doentes com esquemas de prevenção odontológica. Int. Dent. J., England, v. 43, supl. 1, p. 294-298, 1993.

BRANDÃO, I. M. G. Avaliação do conhecimento e de atitudes relacionadas à saúde bucal: gestantes dos Centros Municipais de Saúde de Araraquara - SP. 1998. Dissertação (Mestrado) - Faculdade de Odontologia de Araraquara. Araraquara, 1998.

BRASIL, Ministério da Saúde, Secretaria de Atenção à Saúde, Departamento de Atenção Básica. Projeto SB Brasil 2003: condições de saúde bucal da população brasileira 20022003. Resultados principais. Brasília: Ministério da Saúde, 2004.

BROOK, U.; HEIM, M.; ALKALAI, Y. Attitude, knowledge and habits of high school pupils in Israel regarding oral health. Patient Educ. Couns., Limerick, v. 27, n. 2, p. 171-175, 1996.

CAMPOS, J. A. D. B.; GARCIA, P. P. N. S. Comparação do conhecimento sobre cárie dental e higiene bucal entre professores de escolas de ensino fundamental. Cienc. Odontol. Bras., São José dos Campos, n. 7, n. 1, p. 58-65, 2004.

CAMPOS, L.; BOTTAN, E. R.; FARIAS, J.; SILVEIRA, E. G. Conhecimento e atitudes sobre saúde e higiene bucal dos professores do ensino fundamental de Itapema - SC. Rev. Odontol. UNESP, Marília, v. 37, n. 4, p. 389-394, 2008.

CHIKTE, U. M.; BRAND, A. A.; LEWIS, H. A.; RUDOLPH, M. J. Suitability of nurses and schoolteachers as oral health educators in Gazankulu - a pilot study. J. Dent. Assoc. S. Afr., South Africa, v. 45, n. 10, p. 452-427, 1990a.

; GILBERT, L. Suitability of teachers as oral health educators. J. Dent. Assoc. S. Afr., South Africa, v. 45, n. 10, p. 429-432, 1990 b.

D’ALMEIDA, H. B.; KAGAMI, N.; MAKI, Y.; TAKAESU, Y. Self-reported oral hygiene habits, health knowledge, and sources of oral health information in a group of Japanese junior high school students. Bull. Tokyo Dent Coll., Tokyo, v. 38, n. 2, p. 123-131, 1997.

DEAN, A. G.; DEAN, J. A.; BURTON, A. H.; DICKER, R. C. Epi Info, Version: a word processing, database and statistic program for epidemiology on microcomputers. Atlanta: Centers for Disease Control, 1990.

FERREIRA, J. M. S.; MASSONI, A. C. L. T.; FORTE, F. D. S.; SAMPAIO, F. C. The knowledge of oral health of undergraduate students of Pedagogy. Interface Comun. Saude Educ., Botucatu, v. 9, n. 17, p. 381-388, 2005.

FOCESI, E. Educação em saúde: repensando a formação de professores. Rev. Bras. Saúde Esc., Campinas, v. 1, n. 2, p. 4-8, 1990.

GARBIN, C.; GARBIN, A.; DOS SANTOS, K.; LIMA, D. Oral health education in schools: promoting health agents. Int. J. Dent. Hyg., Oxford, v. 7,n. 3, p. 212-216, 2009.

GARCIA, P. P. N. S.; DINELLI, W.; SERRA, M. C. Saúde bucal: crenças e atitudes, 
conceitos e educação de pacientes do serviço público. JAO - Jornal de Assessoria ao Odontologista, v. 3, n. 22, p. 36-41, 2000.

LANG, P.; WOOLFOLK, M. W.; FAJA, B. W. Oral health knowledge and attitudes of elementary schoolteachers in Michigan. J. Public. Health Dent., Raleigh, v. 49, n. 1, p. 44-50, 1989.

LINDHE, J. Tratado de Periodontologia Clínica. 2. ed. Rio de Janeiro: Guanabara Koogan, 1992. p. 58-60.

LOUPE, M. J.; FRAZIER P. J. Knowledge and attitudes of schoolteachers toward oral health programs and preventive dentistry. J. Am. Dent. Assoc., Chicago, v. 107, n. 2, p. 229-234, 1983.

MARTINS, V. R.; ABRANTES, F. M.; MIASATO, J. M. Professores como uma importante fonte de informação e promoção de saúde bucal. Pesq. Bras. Odontoped. Clín. Integr., v. 8, n. 1, p. 27-30, 2008.

OLIVEIRA, G. W. Conhecimento e aplicação de métodos de prevenção e controle da cárie dentária e inflamação gengival por professores de 1. ${ }^{\circ}$ grau. 1996. Dissertação (Mestrado em Dentística Restauradora) - Faculdade de Odontologia, Universidade Estadual Paulista. Araraquara, 1996. p. 64.

PAIVA, S. M.; GONÇALVES, D. H. A.; PÉRET, L. R. C. A. Promoção de saúde bucal: programa implantado em escolares da região leste de Belo Horizonte. Rev. Saúde em Debate, Londrina, n. 37, p. 36-39, 1992.

PETERSEN, P. E.; DANILA, I.; SAMOILA, A. Oral health behavior, knowledge, and attitudes of children, mothers, and schoolteachers in Romania in 1993. Acta Odontol. Scand., Oslo, v. 53, n. 6, p. 363-368, 1995.

; ESHENG, Z. Dental caries and oral health behavior situation of children, mothers and schoolteachers in Wuhan, People's Republic of China. Int. Dent. J., London, v. 48, n. 3, p. 210-216, 1998.

; ALEKSEJUNIENE, J.; CHRISTENSEN, L. B.; ERIKSEN, H. M. Kalo. Oral health behavior and attitudes of adults in Lithuania. Acta Odontol. Scand., Oslo, v. 58, n. 6 , p. 243-248, 2000.

ROZIER, R. G.; SUTTON, B. K.; BAWDEN, J. W.; HAUPT, K.; SLADE, G. D.; KING, R. S. Prevention of early childhood caries in North Carolina medical practices: implications for research and practice. J. Dent. Educ., Washington, v. 67, p. 876-885, 2003.

SANTOS, P. A.; RODRIGUES, J. A.; GARCIA, P. P. N. S. Avaliação do conhecimento dos professores do ensino fundamental de escolas particulares sobre saúde bucal. Rev. Odontol. UNESP, Marília, v. 31, n.2, p. 205-214, 2002.

comportamento de higiene bucal de professores de ensino fundamental. Cienc. Odontol. Bras., São José dos Campos, v. 6, n. 1, p. 67-74, 2003. 
SGAN-COHEN, H. D.; SAADI, S.; WEISSMAN, A. Dental knowledge and attitude among Arab schoolteachers in northern Israel. Int. Dent. J., London, v. 49, n. 5, p. 269 274, 1999.

UNFER, B.; SALIBA, O. Avaliação do conhecimento popular e práticas cotidianas em saúde bucal. Rev. Saúde Pública, São Paulo, v. 32, n. 2, p.190-195, 2000.

VASCONCELOS, R.; MATTA, M. L.; PORDEUS, I. A.; PAIVA, S. M. Escola: um espaço importante de informação em saúde bucal para a população infantil. PGR Pós-Grad. Rev. Fac. Odontol., v. 4, n. 3, p. 43-48, 2001.

WYNE, A. H.; AL-GHORABI, B. M.; AL-ASIRI, Y. A.; KHAN, N. B. Caries prevalence in Saudi primary schoolchildren of Riyadh and their teachers' oral health knowledge, attitude and practices. Saudi Med. J., Riyadh, v. 23, n. 1, p. 77-81, 2002.

Texto recebido em 27 de abril de 2011.

Texto aprovado em 24 de janeiro de 2013. 